\title{
Jogos Evolutivos, Sistemas Adaptativos Complexos e a Perspectiva Austríaca de Hayek: Uma Discussão Preliminar
}

\author{
Claudio A. Téllez-Zepeda*
}

\begin{abstract}
Resumo: A Escola Austríaca de Economia e a Economia Evolutiva são duas perspectivas heterodoxas aparentemente incompatíveis. O propósito deste artigo é ser um primeiro passo no desenvolvimento de uma abordagem ao mesmo tempo evolutiva e austríaca. Defendo que uma das coisas que impedem o desenvolvimento de uma tal abordagem é o recurso de F. A. Hayek à seleção de grupo em sua interpretação evolutiva dos mercados e da sociedade. Argumento que pode-se desenvolver uma abordagem austríaca evolutiva mediante uma interpretação dos jogos evolutivos como sistemas adaptativos complexos, abandonando a ideia de seleção de grupo e introduzindo uma unidade de seleção adequada.
\end{abstract}

Palavras-Chave: Economia Austríaca, Economia Evolutiva, Teoria Evolutiva dos Jogos, Sistemas Adaptativos Complexos, Memes.

\section{Evolutionary Games, Complex Adaptive Systems and Hayek's Austrian Perspective: A Preliminary Discussion}

\begin{abstract}
The Austrian School of Economics and Evolutionary Economics are two apparently incompatible heterodox approaches. The purpose of this paper is to advance an initial step towards the development of an approach that is both evolutionary and Austrian. I contend that one of the barriers to such an approach is the fact that F. A. Hayek resorted to group selection in his evolutionary interpretation of the markets and society. I argue that it is possible to develop an evolutionary Austrian perspective by interpreting evolutionary games as complex adaptive systems, abandoning the idea of group selection and introducing a proper selection unit.
\end{abstract}

Keywords: Austrian Economics; Evolutionary Economics; Evolutionary Game Theory; Complex Adaptive Systems; Memes.

Classificação JEL: B41, B52, B53, C73

\footnotetext{
* Claudio A. Tellez-Zepeda é professor agregado do Instituto de Relações Internacionais da Pontifícia Universidade Católica do Rio de Janeiro (IRI/PUC-Rio) e membro do Conselho Editorial dos periódicos MISES: Revista Interdisciplinar de Filosofia, Direito e Economia e COMMUNIO: Revista Internacional de Teologia e Cultura. Cursou o bacharelado em Matemática Aplicada na PUC-Rio, o bacharelado em Relações Internacionais no Centro Universitário da Cidade (UniverCidade), o MBA em Gestão de Comércio Exterior e Negócios Internacionais na Fundação Getúlio Vargas (FGV-RJ), bem como o mestrado e o doutorado em Relações Internacionais no IRI/PUC-Rio. Seus interesses de pesquisa incluem Economia Austríaca, Teoria Evolutiva dos Jogos e Sistemas Adaptativos Complexos.

E-mail: tellez.ca@gmail.com
} 


\section{INTRODUÇÃO}

No início do ano 2000, o físico Stephen W. Hawking afirmou que o século XXI será o século da ciência da complexidade ${ }^{1}$. Apesar de não ser uma posição consensual no ambiente das ciências naturais², é inegável que, durante as últimas décadas, avanços na ciência dos sistemas complexos e em áreas correlatas têm proporcionado uma melhor compreensão de diversos fenômenos em áreas variadas. $\mathrm{Na}$ atualidade, testemunhamos uma crescente proliferação de aplicações da abordagem da complexidade - com diversos graus de rigor metodológico - em campos do conhecimento tão distintos como a física, biologia, medicina, climatologia, ciências sociais e economia, só

${ }^{1}$ HAWKING, Stephen W. “Unified Theory Is Getting Closer", Hawking Predicts. Entrevista em: San Jose Mercury News. Morning Final Edition. January 23, 2000. p. 29A.

${ }^{2}$ A resistência de grande parte da comunidade científica à abordagem da complexidade decorre do fato de que há uma considerável produção que a considera como um novo paradigma "científico" (no sentido kuhniano), exaltando seu suposto potencial para solapar a ciência moderna tradicional, que consideram mecanicista e determinista, e colocar em seu lugar uma nova "ciência" holística pós-moderna, que flerta com motivos da Nova Era e com ideologias soteriológicas que prometem uma transformação radical da condição humana. Tal transformação brotaria da alegada integração de temas tais como "mente e consciência", "vida", "ecologia" e, obviamente, alguma coisa aleatória que envolva a palavra "quântico". Há, por outro lado, uma abordagem estritamente científica da complexidade, que pode ser associada à fundação do Santa Fe Institute e que é reconhecida como disciplina organizada há apenas aproximadamente 30 anos (BRAGIN, John. Resenha de "Complexity: A Guided Tour", de Melanie Mitchell. The Journal of Artificial Societies and Social Simulation, Vol. 13, No. 2, March 2010. Disponível em: <http://jasss. soc.surrey.ac.uk/13/2/reviews/3.html>). É necessário esclarecer que esta última é a abordagem que orienta esta pesquisa. Para uma apresentação panorâmica da ciência da complexidade, ver: MITCHELL, Melanie. Complexity: A Guided Tour. New York: Oxford University Press, 2009; GELL-MANN, Murray. What is Complexity? Remarks on Simplicity and Complexity by the Nobel Prize-winning Author of The Quark and the Jaguar. Complexity, Vol. 1, No. 1 (1995): 16-19. para citar alguns exemplos. No caso particular da Escola Austríaca de Economia, entretanto, o diálogo entre acadêmicos austríacos e cientistas da complexidade não tem se desenvolvido de maneira significativa nos últimos anos. Apesar de F. A. Hayek (1899-1992) ter dedicado parte considerável de seus últimos trabalhos à investigação dos processos de emergência da ordem espontânea em sistemas sociais e econômicos ${ }^{3}$, um tema que remeteimediatamente a ideias centrais da ciência da complexidade, a tradicional resistência dos acadêmicos austríacos com respeito à possibilidade de integração com as ciências naturais e a matemática ainda pesa muito no delineamento das agendas austríacas de pesquisa.

Ao mesmo tempo, dentre as diversas correntes que compõem o que se pode chamar de heterodoxia na ciência econômica, a Economia Austríaca e a Economia Evolutiva figuram como sérias alternativas à perspectiva do mainstream, ou neoclássica. A Economia Evolutiva interpreta as mudanças que ocorrem em diversos aspectos da economia (p. ex. em mercadorias, tecnologias e instituições) como processos evolutivos, em franca analogia com o processo de evolução biológica ${ }^{4}$. A Economia Austríaca, por sua vez, também enfatiza o processo e a mudança na economia, porém acrescenta o elemento central do indivíduo, que interpreta subjetivamente os dados da realidade econômica na condução de suas ações intencionais. Contudo, no que concerne a uma compatibilização entre essas duas abordagens, Ulrich Witt indica que há diversos pontos problemáticos na Economia Evolutiva ${ }^{5}$

${ }^{3}$ HAYEK, F. A. The Results of Human Action but Not of Human Design. In: HAYEK, F. A. New Studies in Philosophy, Politics, Economics. Chicago: University of Chicago Press, 1978. p. 96-105.

${ }^{4}$ SHIOZAWA, Y. Evolutionary Economics in the 21st Century: A Manifesto. Evolutionary and Institutional

Economics Review, Vol. 3, No. 2 (2004): 5-47. De acordo com Shiozawa, a Economia Evolutiva demanda um marco teórico novo e totalmente distinto da Economia Neoclássica (p. 26).

${ }^{5}$ WITT, Ulrich. Evolution as the Theme of a New Heterodoxy in Economics. In: WITT, Ulrich (Ed.). 
e Alexander $\mathrm{H}$. Shand evidencia pontos de discordância explícitos existentes entre essas duas correntes ${ }^{6}$. Mais especificamente, Witt observa que a metodologia apriorista de Ludwig von Mises (1881-1973) é difícil de reconciliar com a abordagem evolutiva, que pede uma postura metodológica falibilista e empírica, e que a Economia Evolutiva, de matriz schumpeteriana, não dá atenção suficiente aos aspectos subjetivos ${ }^{7}$ indissociáveis de qualquer tratamento que se pretenda considerar austríaco.

Ulrich Witt está certo ao observar que uma compatibilização das perspectivas austríaca e evolutiva deve, necessariamente, levar em conta o problema da subjetividade dos agentes individuais 8 . O autor também reconhece - a meu ver, corretamente - que a abordagem hayekiana para a evolução cultural (baseada na ideia de seleção de grupo) "não parece reconciliável com uma perspectiva individualista". Witt considera, contudo, que mesmo que Hayek baseie-se em um critério de "sucesso de grupo", sem explorar a relação entre o nível do grupo e o nível dos indivíduos, isso não significa que sua teoria seja incompatível com a abordagem individualista ${ }^{10}$. Nesse ponto, estou em desacordo com Witt e defendo, como ficará claro nas seções subsequentes, que a ideia de seleção de grupo pode e deve ser abandonada para o desenvolvimento de uma perspectiva econômica realmente evolutiva.

Explaining Process and Change: Approaches to Evolutionary Economics. Ann Arbor: Michigan University Press, 1992. p. 3-20.

${ }^{6}$ SHAND, Alexander H. Subjectivist Economics: The New Austrian School. Oxford: Short Run Press, 1981.

7 WITT, Ulrich. Turning Austrian Economics into an Evolutionary Theory. In: CALDWELL, Bruce J. \& BOEHM, Stephan (Eds.). Austrian Economics: Tensions and New Directions. New York: Springer, 1992. p. 215-236.

${ }^{8}$ Idem. Ibidem., p. 230.

${ }^{9}$ Idem. Ibidem., p. 227.

${ }^{10}$ Idem. Ibidem., p. 228.
Assim, meu principal argumento neste artigo é que, apesar de terem se desenvolvido como duas posições heterodoxas distintas no espectro teórico da economia, e não obstante as dificuldades epistemológicas e metodológicas envolvidas nas tentativas de compatibilizá-las, é possível desenvolver uma perspectiva que é, ao mesmo tempo, evolutiva e austríaca. O propósito deste artigo é ser um primeiro passo - uma discussão preliminar - exatamente nessa direção. Para tanto, considero necessário interpretar os jogos evolutivos como exemplos de sistemas adaptativos complexos e identificar uma unidade adequada de seleção, de modo a possibilitar a aplicabilidade da proposta teórica a temas e problemas econômicos específicos.

O núcleo do meu argumento é que o que dificulta o desenvolvimento de uma abordagem austríaca plenamente evolutiva (ao invés de uma mera analogia com processos evolutivos) é exatamente o fato de que Hayek fundamentou suas análises na ideia de "seleção de grupo". Abandonando a ideia de seleção de grupo, contudo, tornase possível trabalhar com os jogos evolutivos como sistemas adaptativos complexos, sem abandonar o individualismo metodológico subjetivo que é tão característico da perspectiva austríaca. Além disso, através do casamento da teoria evolutiva dos jogos com os sistemas complexos adaptativos, minha abordagem envolve elementos tais como "processo no tempo" e "conhecimento sempre necessariamente local e incompleto", características importantes que devem ser consideradas no estudo dos sistemas adaptativos complexos compostos por múltiplos agentes sociaishumanos individuais que interagem em um determinado ambiente em constante mudança.

$\mathrm{Na}$ próxima seção, apresentarei com um pouco mais de detalhes (ainda que brevemente) algumas questões epistemológicas que conformam a resistência dos austríacos com respeito a uma maior integração com temas científicos e matemáticos. Argumenta- 
rei que tal resistência não mais se sustenta na contemporaneidade. Na terceira seção, discutirei a relação entre sistemas complexos adaptativos e jogos evolutivos, mostrando como os aspectos da ação humana individual, do tempo e do conhecimento estão presentes nessa relação. Dessa maneira, argumentarei que os jogos evolutivos, entendidos como sistemas complexos adaptativos, satisfazem aos critérios de "austricidade" tal como apresentados por Ubiratan Jorge Iorio $^{11}$. Na quarta seção, farei uma crítica à postura hayekiana da seleção de grupo. Para abandonar a seleção de grupo e resgatar o individualismo metodológico subjetivo, possibilitando assim a utilização de jogos evolutivos para investigar questões econômicas e sociais sob uma perspectiva austríaca, desenvolvo o argumento de que podemos trabalhar com a proposta dos memes, introduzida pelo biólogo evolucionista Richard Dawkins em seu livro de $1976^{12}$. Será nessa seção, portanto, que fecharei meu argumento principal. A quinta e última seção será dedicada às minhas considerações finais, nas quais apresentarei algumas possibilidades de aplicação da abordagem proposta, bem como temas e problemas a serem desenvolvidos em trabalhos subsequentes.

\section{I - Dirigindo PELO ESPELHO Retrovisor: A Conturbada Relação entre a EConomia Austríaca, a Matemática e as CiênCias Naturais}

Devo esclarecer que não é meu propósito, nesta seção, elaborar uma discussão filosófica/ epistemológica detalhada a respeito dos problemas que existem na relação entre Economia Austríaca, matemática e ciências naturais.

${ }^{11}$ IORIO, Ubiratan Jorge. Ação, Tempo e Conhecimento: A Escola Austríaca de Economia. São Paulo: Instituto Ludwig von Mises Brasil, 2011.

12 DAWKINS, Richard. The Selfish Gene: 30th Anniversary Edition. Oxford: Oxford University Press, 2006.
Trata-se de uma discussão inegavelmente importante a título de fundamentação e que, por isso mesmo, deixo a cargo de autores verdadeiramente competentes para lidar com os meandros da discussão filosófica. Meu objetivo aqui é muito mais modesto. Pretendo apenas chamar a atenção para o fato de que a resistência de parte de muitos austríacos para lidar com temas de matemática e de ciências naturais apresenta-se como obstáculo ao tipo de proposta que avanço neste artigo. Identifico que a resistência do "mainstream austríaco" ocorre principalmente (ainda que não unicamente) em duas frentes: (1) contra a utilização de modelos formais (matemáticos) na pesquisa econômica de orientação austríaca; (2) contra a possibilidade de qualquer embasamento metodológico que esteja de acordo com a concepção presente nas ciências assim chamadas "naturais". Ao longo desta seção, procurarei responder a essas duas frentes.

No primeiro caso, a respeito da utilização de modelos formais (matemáticos) na Economia Austríaca, minha primeira observação diz respeito à necessidade de esclarecer que a matemática não se resume à aplicação de métodos quantitativos ou estatísticos, ou à modelagem de processos determinísticos. Estou de acordo com a essência da crítica de Ludwig von Mises ao papel da estatística e das abordagens quantitativas na economia. Mises defende que a estatística é a apresentação sistemática de dados do passado e que, por causa disso, é história econômica, e não economia. Enfatizando o aspecto dinâmico do processo econômico, Mises afirma que:

A estatística é um método para apresentação de fatos históricos relativos a preços e outros dados relevantes da ação humana. Não é economia e não pode produzir teoremas ou teorias econômicas. A estatística de preços é história econômica. [...] O que costumam chamar de economia quantitativa simplesmente não existe. Todas as quantidades econômicas que conhecemos são dadas da história econômica. ${ }^{13}$

${ }^{13}$ MISES, Ludwig von. Ação Humana: Um Tratado 
Mises não se equivoca ao elaborar essa caracterização da estatística e da economia quantitativa. Entretanto, é um erro corrente considerar que a matemática, tal como a estatística, ocupa-se unicamente do tratamento quantitativo. Estou ciente de que não há uma única definição de matemática, e de que aspectos quantitativos também fazem parte da matemática. Contudo, estamos muito distantes da concepção aristotélica da matemática como "ciência da quantidade"14. Atualmente, a matemática lida, mais propriamente, com a identificação e análise de relações e padrões utilizando processos abstratos de raciocínio. Assim, a matemática pode envolver aspectos quantitativos, mas não se resume a eles. Da mesma forma, é um equívoco considerar a matemática como uma mera ferramenta à disposição de uma epistemologia de matiz positivista.

Chamo a atenção, aqui, para a célebre distinção de Frank Knight (1885-1972) entre risco e incerteza ${ }^{15}$, segundo a qual o risco é uma incerteza mensurável, enquanto nada podemos dizer, em termos de conteúdo de informação, acerca da incerteza. Entretanto, o fato de que há incerteza genuína em grande parte das situações enfrentadas pelos agentes econômicos na vida real não significa que sejam situações intratáveis matematicamente; significa apenas que são situações não quantificáveis mediante o emprego de técnicas probabilísticas ou estatísticas convencionais. Mas ainda podese empregar a matemática para estudar a incerteza qualitativamente. $\mathrm{Na}$ verdade, existe uma área chamada Teoria da Incerteza,

de Economia. TQradução de Donald Stewart Jr. São Paulo: Instituto Ludwig von Mises Brasil, 2010. p. 413.

${ }^{14}$ Para uma extensa discussão a este respeito, remeto o leitor a: FRANKLIN, James. An Aristotelian Realist Philosophy of Mathematics: Mathematics as the Science of Quantity and Structure. New York: Palgrave Macmillan, 2014.

${ }^{15}$ KNIGHT, Frank H. Risk, Uncertainty, and Profit. Chicago: Hart, Schaffner \& Marx, 1921. que é exatamente a parte da matemática que lida com o estudo da incerteza humana no mundo real ${ }^{16}$.

Outra razão para a resistência de muitos austríacos para com a matemática decorre das colocações de Murray N. Rothbard (19261995), que defendia a ideia de que a matemática realiza operações dedutivas sobre símbolos desprovidos de significado em si mesmos ${ }^{17}$. A utilidade da matemática na ciência física decorre justamente do fato de que os tanto os axiomas quanto as leis deduzidas a partir dos axiomas possuem significado meramente operacional, ou seja, são úteis para explicar fatos referentes ao mundo natural, que não possuem significado em si mesmos. No caso da economia austríaca, em contraste, lidamos desde o início com o axioma da ação humana, que possui significado em si mesmo. Dessa maneira, como os desenvolvimentos matemáticos necessariamente lidam com símbolos que não têm significado, então utilizá-los produziria o efeito desagradável de eliminar o significado da própria economia.

A concepção rothbardiana dematemática descrita acima é discutível, para não dizer ingênua ${ }^{18}$. Primeiramente, por reduzir a matemática à mera "realização de operações dedutivas sobre símbolos"19. O tratamento de Rothbard representa a matemática como uma linguagem de ligação ou mediação que não faria mais pela economia do que "traduzir símbolos verbais em simbolos formais sem significado" ${ }^{20}$. Dessa maneira, ele simplesmente

16 LIU, Baoding. Uncertainty Theory: A Branch of Mathematics for Modeling Human Uncertainty. Berlin: Springer-Verlag, 2010.

${ }^{17}$ ROTHBARD, Murray No. A Note on Mathematical Economics. Mises Daily, September 1, 2009. Disponível em: <http://mises.org/library/note-mathematicaleconomics>.

${ }^{18} \mathrm{O}$ que é de certo modo surpreendente, dado que Rothbard teve treinamento formal em matemática na Universidade de Columbia, em New York.

${ }^{19}$ ROTHBARD, Murray No. A Note on Mathematical Economics.

${ }^{20}$ Idem. Ibidem. 
assume que a matemática é subserviente à interpretação epistemológica positivista das ciências naturais e a considera como uma mera manipulação linguística, sem sequer entrar no mérito das diversas posições ontológicas e epistemológicas existentes a respeito da matemática ${ }^{21}$. No entanto, existe um debate considerável a respeito do status ontológico das entidades matemáticas e grande parte dos matemáticos profissionais "são relutantes quanto a referir-se aos 'conceitos por trás dos símbolos' como desprovidos de significado" 22 . A posição de Rothbard é, portanto, muito mais idiossincrática e retórica do que verdadeiramente embasada nas discussões correntes - em sua época - a respeito da natureza da matemática, o que torna arriscado considerá-la como "a" postura definitiva dos austríacos com respeito à possibilidade de desenvolver tratamentos matemáticos sobre temas e problemas da Economia Austríaca.

Em 1959, o físico Eugene Wigner (19021995) proferiu uma palestra intitulada "The Unreasonable Effectiveness of Mathematics in the Natural Sciences", na qual expressou seu assombro com relação às regularidades matemáticas presentes no funcionamento de diversos processos naturais ${ }^{23}$. Instigado pelas reflexões de Wigner, o físico e cosmólogo sueco Max Tegmark, do Massachussets Institute of Technology (MIT), recentemente sugeriu uma solução para esse enigma postulando a hipótese de que a própria

\footnotetext{
${ }^{21}$ Para uma apresentação geral, ver SHAPIRO, Stewart. Thinking about Mathematics: The Philosophy of Mathematics. New York: Oxford University Press, 2000. Para um tratamento mais técnico, remeto a: BENACERRAF, Paul \& PUTNAM, Hilary (Eds.). Philosophy of Mathematics: Selected Readings. Cambridge: Cambridge University Press, 1984.

22 RAVITCH, Harold. On Gödel's Philosophy of Mathematics. Tese de Mestrado. Los Angeles, University of California, 1968. Disponível em: <http:// www.friesian.com/goedel/>.

${ }^{23}$ WIGNER, Eugene. The Unreasonable Effectiveness of Mathematics in the Natural Sciences. Communications in Pure and Applied Mathematics, Vol. 13, No. 1 (February 1960): 1-14.
}

estrutura da realidade seria, em última análise, matemática (isto é, a realidade física não seria meramente descrita pela matemática, mas sim seria matemática $)^{24}$. Se Tegmark estiver certo, a resposta para a vida, o universo e tudo mais estaria contida nesse substrato matemático último. Independente da validade ou não da proposta de Tegmark, trata-se de uma ideia que minimamente nos coloca diante da necessidade de abordar com mais cuidado a relação entre matemática e conhecimento em geral.

Finalmente, Nicolai Foss observa que Mises rejeita explicitamente - e até pejorativamente - a utilização da teoria dos jogos na pesquisa em Economia Austríaca ${ }^{25}$. Nas palavras de Mises:

Numa sociedade regida pelos princípios do mercado livre, não há a menor analogia entre a participação em jogos e a condução de negócios. O jogador de cartas ganha dinheiro de seu antagonista servindo-se de habilidades e astúcias. O empresário ganha dinheiro fornecendo aos consumidores os bens que desejam adquirir. Pode haver uma analogia entre o jogador de cartas e o blefista. Não há necessidade de aprofundamento neste assunto. Quem considerar a condução de negócios como trapaça está na pista errada. ${ }^{26}$

Foss nota, acertadamente, que a crítica de Mises pode até ser adequada para uma concepção arcaica da teoria dos jogos. Contudo, essa teoria avançou muito desde a época das colocações de $\mathrm{Mises}^{27}$. O ponto que desejo ressaltar é que Nicolai Foss chama a atenção para o fato de que a moderna teoria dos jogos deve muito à Escola Austríaca de Economia em seus desenvolvimentos seminais

\footnotetext{
${ }^{24}$ TEGMARK, Max. Our Mathematical Universe: My Quest for the Ultimate Nature of Reality. New York: Alfred A. Knopf, 2014.

25 FOSS, Nicolai. Austrian Economics and Game Theory: A Stocktaking and an Evaluation. Review of Austrian Economics, Vol. 13 (2000): 41-58.

${ }^{26}$ MISES. Ação Humana. p. 151.

${ }^{27}$ FOSS. Austrian Economics and Game Theory. p. 47.
} 
e pode inclusive ser considerada como parte da tradição austríaca ${ }^{28}$. Oskar Morgenstern (1902-1977), co-autor de John von Neumann (1903-1957) na obra que deu origem à moderna teoria dos jogos ${ }^{29}$, foi um economista austríaco que frequentou o Privatseminar de Mises em Viena. Yvan J. Kelly recorda que John Nash, que recebeu o Prêmio de Ciências Econômicas em Memória de Alfred Nobel em 1994, devido ao seu teorema do equilíbrio, foi diretamente influenciado por Bert F. Hoselitz (1913-1995) ${ }^{30}$, um economista austríaco que estudou com Mises $^{31}$.

A partir do exposto acima, concluo que algumas das principais razões para a resistência dos acadêmicos austríacos com respeito à matemática não se sustentam, por estarem baseadas em concepções extremamente limitadas e inclusive ingênuas a respeito da natureza da matemática e da atividade dos matemáticos. Ademais, no caso específico da teoria dos jogos, a relação dessa área da matemática com a Escola Austríaca não pode ser desconsiderada, já que os desenvolvimentos iniciais na matemática dos jogos deveram muito às reflexões suscitadas pela Escola Austríaca.

O segundo caso, sobre a oposição a qualquer embasamento metodológico que esteja de acordo com a concepção presente nas ciências assim chamadas "naturais", é um ponto que merece mais cautela. Esclareço, de início, que não defendo que a economia, ou que as áreas sociais em geral, devam "imitar" ou ter por objetivo seguir o modelo ideal da física como ciência. Na verdade, o excesso de otimismo que caracterizou a ciência como atividade capaz de resolver todo e qualquer

\footnotetext{
${ }^{28}$ Idem. Ibidem., p. 49.

${ }^{29}$ NEUMANN, John von \& MORGENSTERN, Oskar. The Theory of Games and Economic Behavior. Princeton, NJ: Princeton University Press, 1953 [1944].

${ }^{30}$ KELLY, Yvan J. Mises, Morgenstern, Hoselitz, and Nash: The Austrian Connection to Early Game Theory. The Quarterly Journal of Austrian Economics, Vol. 12, No. 3, p. 37-42, 2009.

${ }^{31}$ Idem. Ibidem., p. 38-39.
}

questionamento podia até fazer sentido nos séculos XVIII e XIX, mas na atualidade temos um entendimento bem mais modesto a respeito dos limites e capacidades do empreendimento científico. De acordo com Mises, em sua cuidadosa discussão a respeito dos problemas epistemológicos do estudo da ação humana:

Ocorre, entretanto, que as ciências da ação humana são radicalmente diferentes das ciências naturais. Todos os autores que pretendem estabelecer uma base epistemológica das ciências da ação humana segundo o padrão das ciências naturais erram lamentavelmente ${ }^{32}$.

Em outra parte ${ }^{33}$, Mises esclarece que, enquanto as ciências naturais são voltadas para a pesquisa da causalidade, o estudo da ação humana, por sua vez, é teleológico ${ }^{34}$. No caso específico da teoria da seleção natural de Charles Darwin (1809-1882), Mises observa que:

O conceito darwiniano de seleção natural tenta explicar a mudança filogenética sem recorrer à finalidade como um fenômeno natural. A seleção natural opera não somente sem nenhuma interferência propositada por parte de elementos externos; opera também sem qualquer comportamento intencional de parte dos diversos espécimes em consideração $0^{35}$.

Se a crítica de Mises refere-se à empresa ambiciosa de adequar a economia ao arcabouço epistemológico e metodológico das ciências naturais, estou de acordo. Com relação ao aspecto teleológico estar ausente das partículas materiais estudadas pela física, também concordo. Contudo, tenho minhas dúvidas com relação à leitura misesiana da seleção natural, pois, com relação a questões

\footnotetext{
${ }^{32}$ MISES. Ação Humana. p. 67.

${ }^{33}$ MISES. The Ultimate Foundation of Economic Science: An Essay on Method. Indianapolis: Liberty Fund, 2006.

${ }^{34}$ Idem. Ibidem., p. 6.

${ }^{35}$ Idem. Ibidem., p. 13.
} 
que envolvem a ideia de mente (intencional ou não), alinho-me com neurocientista colombiano Rodolfo R. Llinás, para quem " $a$ mente resulta de processos evolutivos [...] [e] uma investigação real da base científica para o estado de mentalidade requer uma rigorosa perspectiva evolutiva" ${ }^{\prime 3}$. O fato da seleção natural não exigir propósito de parte dos indivíduos para o seu funcionamento não significa, a priori, que elementos de intencionalidade não possam participar de processos evolutivos específicos $^{37}$. Mais ainda, é perfeitamente plausível que os processos mentais subjacentes às escolhas propositadas e subjetivas dos indivíduos humanos sejam, assim como a mente, resultado de processos evolutivos.

Se as reservas de Mises e de outros economistas austríacos dizem respeito ao risco de incorrer em práticas reducionistas, cabe fazer uma clarificação, dado que há uma certa confusão com respeito ao que significa ser reducionista. Seguindo a distinção elaborada pelo filósofo Daniel Dennett, entendo o "reducionismo bom" como aquele que tenta explicar um objeto ou um processo em termos de suas partes e interações, reconhecendo que o todo é mais do que a soma de seus componentes individuais e que as complexidades devem ser levadas em conta no processo de análise. Já o "reducionismo ganancioso" acontece quando:

Em seu afã para explicar muitas coisas, e muito rapidamente, cientistas e filósofos [...] subestimam as complexidades, tentando saltar camadas ou níveis de teoria inteiros em sua corrida para fixar tudo aos fundamentos, de forma segura e ordenada ${ }^{38}$.

\footnotetext{
${ }^{36}$ LLINÁS, Rodolfo R. I of the Vortex: From Neurons to Self. Cambridge: MIT Press, 2002. p. ix.

37 A teoria evolutiva dos jogos não pressupõe necessariamente que o comportamento dos jogadores é racionalmente orientado, como ocorre com a teoria dos jogos tradicional ou convencional. O que não quer dizer que, em um jogo evolutivo, escolhas conscientes e propositadas não possam desempenhar um papel na evolução do sistema.

${ }^{38}$ DENNETT, Daniel C. Darwin's Dangerous Idea: Evolution and the Meanings of Life. London: Penguin, 1996. p. 82.
}

Rejeito o reducionismo ganancioso - e suspeito que a maior parte dos economistas austríacos estariam de acordo comigo. No entanto, não rejeito o "reducionismo bom", por considerar que está de acordo com o próprio programa de pesquisa da Escola Austríaca, que procura entender os processos econômicos a partir do estudo dos indivíduos e de suas interações, sem desconsiderar as complexidades no processo de análise.

Finalmente, algumas reflexões de Henry Hamman, dirigidas ao público de Relações Internacionais, são totalmente pertinentes a esta discussão ${ }^{39}$. De acordo com Hamman:

[...] um outro fator que se acrescenta à dificuldade para discutir as possíveis contribuições das ciências naturais e da matemática para o entendimento do mundo social é a falta de conhecimento, por parte da comunidade das ciências sociais, com respeito aos desenvolvimentos da ciência no século XX. ${ }^{40}$

Mais ainda, [...] a maior parte dos modelos de relações internacionais baseiam-se nos pressupostos intelectuais da física newtoniana: o universo totalmente determinado, que funciona como um relógio. A física de Newton é uma tentativa de explicar os aspectos regulares da vida. Nas relações internacionais, contudo, não estamos interessados nas regularidades, mas sim na irregularidade. Assim, os modelos baseados no relógio são inapropriados, pois não permitem irregularidades e, quando as irregularidades aparecem, os modelos são considerados como fracassados.

Mas o problema central é de certo modo mais tratável: não é que a ciência tenha

39 HAMMAN, Henry L. Remodeling International Relations: New Tools from New Science? In: KUBÁLKOVÁ, Vendulka ; ONUF, Nicholas \& KOWERT, Paul (Eds.). International Relations in a Constructed World. Armonk: M. E. Sharpe, 1998. p. 173-92.

${ }^{40}$ Idem. Ibidem., p. 173. 
falhado, mas sim que emulamos a ciência errada, a ciência dos séculos XVIII e XIX, em vez da ciência de fins do século $X X^{41}$.

Ou seja, além da falta de conhecimento técnico a respeito do que vem sendo feito nas ciências naturais ao longo das últimas décadas, muitos críticos das áreas sociais têm em mente que propostas de tratamento científico, ou de diálogo interdisciplinar, pretendem enquadrar os problemas das áreas sociais ao ideal científico dos séculos XVIII e XIX. Persistir nessa linha corresponde a continuar dirigindo pelo espelho retrovisor. Grande parte do debate epistemológico tradicional da Escola Austríaca é, portanto, datado e deve ser atualizado para voltar a acompanhar o ritmo da produção de conhecimento no século XXI.

Na próxima seção, apresentarei o que são jogos evolutivos, o que são sistemas adaptativos complexos e mostrarei que a matemática e as ciências naturais não estão em desacordo com critérios fundamentais de "austricidade".

\section{II - Sistemas Adaptativos Complexos, Jogos Evolutivos e Ação Humana}

Nesta seção, discutirei a relação entre sistemas complexos adaptativos e jogos evolutivos, mostrando como os aspectos da ação humanaindividualesubjetiva, dotempodinâmico e do conhecimento limitado estão presentes nessa relação. Dessa maneira, argumentarei que os jogos evolutivos, entendidos como sistemas complexos adaptativos, satisfazem aos critérios de "austricidade", tal como apresentados por Ubiratan Iorio em sua obra Ação, Tempo e Conhecimento: A Escola Austríaca de Economia ${ }^{42}$.

De acordo com Ubiratan Iorio, os traços distintivos e fundamentais da Escola Austríaca

\footnotetext{
${ }^{41}$ Idem. Ibidem., p. 179.

${ }^{42}$ IORIO. Ação, Tempo e Conhecimento.
}

de Economia formam uma tríade básica (núcleo fundamental) composta pelos conceitos de ação humana, de tempo dinâmico e de conhecimento limitado ${ }^{43}$. A ação, de acordo com Iorio, é um ato voluntário e deliberado que tem por objetivo passar de um estado menos satisfatório para outro, que é considerado mais satisfatório no momento da escolha. O tempo dinâmico definese como o fluxo irreversível e permanente de novas experiências, que possibilita a evolução criativa. Finalmente, o conhecimento é considerado como limitado, já que agentes econômicos precisam lidar com incerteza genuína (não mensurável probabilisticamente) e a mente humana é incapaz de "compreender integralmente a complexidade dos fenômenos sociais e econômicos"44. Além dessa tríade, é importante destacar o subjetivismo da Escola Austríaca que, de acordo com Iorio, está subordinado ao individualismo metodológico e refere-se ao pressuposto de que o conteúdo da mente humana não é determinado por eventos externos $^{45}$. Assim, uma abordagem evolutiva compatível com a perspectiva austríaca precisa, minimamente, conter esses três elementos da tríade básica. Observo ainda que o primeiro elemento, da ação humana, é indissociável do individualismo metodológico subjetivo.

Para meus propósitos, baseio-me na concepção de sistema adaptativo complexo delineada pelo matemático Simon A. Levin, para quem as três propriedades que definem um tal sistema são:

[...] diversidade e individualidade dos componentes, interações localizadas entre esses componentes e um processo autônomo que utiliza os resultados dessas interações para selecionar um subconjunto desses componentes para replicação ou aprimoramento ${ }^{46}$.

\footnotetext{
${ }^{43}$ Idem. Ibidem., p. 17.

${ }^{44}$ Idem. Ibidem., p. 18-19.

${ }^{45}$ Idem. Ibidem., p. 20.

46 LEVIN, Simon A. Complex Adaptive Systems: Exploring the Known, the Unknown and the Unknowable. Bulletin (New Series) of the American Mathematical Society, Vol. 40, No. 1 (2002): 3-19.
} 
Ao mesmo tempo, Andrew Ilachinski, que utiliza a dinâmica não-linear e a teoria dos sistemas complexos para estudar os processos fundamentais do combate terrestre, define um sistema adaptativo complexo como "um sistema complexo cujas partes também podem evoluir e adaptar-se a um ambiente em mudança" ${ }^{\prime 4}$.

A primeira das propriedades de Levin caracteriza as individualidades que estão presentes em um sistema complexo. A segunda propriedade enfatiza que agentes individuais tendem a interagir, em sua maior parte, com seus vizinhos próximos (interações a distâncias maiores são possíveis, porém mais raras). Finalmente, a terceira propriedade descreve a conexão entre os sistemas adaptativos complexos e a lógica adaptativa evolutiva: a seleção para replicação, de acordo com a adaptação adequada às mudanças no ambiente.

Dado que a primeira propriedade de Levin é a "diversidade e individualidade dos componentes", isso indica que o individualismo metodológico não é incompatível com os sistemas adaptativos complexos. Ademais, Ilachinski identifica, como característica essencial dos sistemas complexos, o fato de ocorrer a interação tipicamente não-linear de muitas partes heterogêneas ${ }^{48}$. No caso de sistemas adaptativos complexos nos quais os componentes são indivíduos humanos, a caracterização dos agentes como "partes heterogêneas" está de acordo com o aspecto individual subjetivo presenteno tratamento da ação humana. Indivíduos humanos distintos agem de forma propositada e subjetivamente orientada, formando assim um conjunto de partes heterogêneas.

Um tratamento adequado da complexidade também requer o abandono do conceito newtoniano de tempo absoluto. A concepção bergsoniana de tempo como duração ${ }^{49}$ é mais adequada para o tratamento

\footnotetext{
${ }^{47}$ ILACHINSKI, A. Artificial War: Multiagent-Based Simulation of Combat. Singapore: World Scientific, 2004. p. 4.

${ }^{48}$ Idem. Ibidem., p. xiii.

${ }^{49}$ Devo esclarecer que Henri Bergson apresentou uma
}

da evolução temporal dos sistemas adaptativos complexos. De acordo com essa concepção, a duração (durée) corresponde à experiência subjetiva do tempo, em vez da concepção objetiva do tempo como sucessão de instantes ou momentos ${ }^{50}$. A duração é um conceito abrangente, que compreende estados psicológicos, tempo e movimento ${ }^{51}$, conformando assim uma temporalidade que se conecta à consciência subjetiva e à memória.

Por meio de seu conceito de duração, Henri Bergson (1859-1941) entendia a evolução como um processo que "envolve a sucessão, a continuidade ou a interpenetração no tempo" ${ }{ }_{52}$. Embora o entendimento bergsoniano de evolução estivesse em desacordo com a perspectiva evolutiva de Darwin, sua concepção de tempo corresponde a um fluxo dinâmico e contínuo de experiências subjetivas que conectam o presente a outros momentos, através das percepções dos agentes individuais ${ }^{53}$. A duração expressa, portanto, nossa experiência da realidade como um fluxo vivo e incessante que envolve a "invenção, a criação de formas, a elaboração contínua do absolutamente novo"54. Assim, a duração bergsoniana pode ser associada a uma perspectiva dinâmica e irreversível do tempo, tal como ocorre nos sistemas adaptativos complexos nos quais os componentes são indivíduos humanos. Cada agente apresenta a sua própria percepção subjetiva do tempo (mesmo que possamos considerar que o sistema, como

explicação alternativa à evolução, diferente da que foi desenvolvida por Charles Darwin. Entretanto, estou interessado somente em sua concepção temporal de duração, que me possibilita considerar o tempo como uma experiência subjetiva.

50 BERGSON, Henri. L'Évolution Créatrice. Paris: Presses Universitaires de France, 1991. p. 4.

${ }^{51}$ FELL, E. Duration, Temporality, Self: Prospects for the Future of Bergsonism. Berlin: Peter Lang, 2012. p. 21.

${ }^{52}$ GALLAGHER, I. J. Morality in Evolution: The Moral Philosophy of Henri Bergson. The Hague: Martinus Nijhoff, 1970. p. 17.

${ }^{53}$ IORIO. Ação, Tempo e Conhecimento. p. 73.

54 BERGSON apud GALLAGHER. Morality in Evolution. p. 17. 
um todo, "evolua" adaptativamente em referência a uma temporalidade fixa e exógena) e orienta suas ações adaptando-se às constantes mudanças no ambiente, que alteram continuamente a maneira como o tempo é percebido pelos próprios agentes individuais.

Finalmente, o aspecto do conhecimento limitado relaciona-se à informação disponível para os componentes de um sistema complexo. Conforme apresentei acima, a segunda propriedade de Levin enfatiza que as interações entre agentes individuais são localizadas. A informação encontra-se dispersa ao longo do sistema, porém um dado agente só consegue trabalhar com porções de informação mais imediatas que decorrem de suas interações com agentes mais próximos. A não-linearidade característica dos sistemas complexos implica na presença de um aspecto de não-previsibilidade, correspondente à necessidade que os agentes econômicos têm de lidarem com a incerteza genuína em seus processos decisórios. Nos sistemas adaptativos complexos, a evolução do sistema decorre das interações entre agentes individuais, porém os agentes individuais não têm acesso ao conteúdo informacional do sistema como um todo. De acordo com Ilachinski:

Os agentes de um sistema complexo tipicamente "veem" (e interagem com) somente uma porção limitada do sistema como um todo, e agem localmente; i.e., a dinâmica inter-agentes é, geralmente, altamente descentralizada. [...] As partes do sistema agem localmente, utilizando somente a informação local ${ }^{55}$.

Dessa maneira, os sistemas adaptativos complexos cujos componentes são indivíduos humanos satisfazem adequadamente os critérios de austricidade delineados por Ubiratan Iorio. Passo, agora, a uma breve discussão sobre jogos evolutivos.

A teoria evolutiva dos jogos começou com o artigo de 1973 de John Maynard Smith (1920-2004) e George R. Price (1922-1975),

${ }^{55}$ ILACHINSKI. Artificial War. p. 107. intitulado "The Logic of Animal Conflict" A seguir, John Maynard Smith desenvolveu mais o assunto em dois ensaios publicados em 1974 e 1976, intitulados respectivamente "The Theory of Games and the Evolution of Animal Conflicts" ${ }^{57} \mathrm{e}$ "Evolution and the Theory of Games"58. Em 1982, John Maynard Smith publicou o livro Evolution and the Theory of Games, no qual apresentou os avanços obtidos na primeira década de aplicações da teoria dos jogos ao estudo da evolução biológica ${ }^{59}$. Nas palavras do autor:

[...] a teoria evolutiva dos jogos é uma maneira de pensar a respeito da evolução no nível fenotípico, quando as aptidões de fenótipos específicos dependem de suas frequências na população ${ }^{60}$.

É importante ressaltar que John Maynard Smith reconheceu que a teoria clássica dos jogos baseia-se no pressuposto central do comportamento racional dos jogadores, de acordo com algum critério de autointeresse, um critério que não é totalmente adequado no campo da teoria evolutiva em biologia. No caso da teoria evolutiva dos jogos, essa racionalidade técnica é substituída pela dinâmica e estabilidade da população, e o autointeresse corresponde à adequação darwiniana ${ }^{61}$. Inicialmente, a teoria evolutiva dos jogos foi desenvolvida como uma maneira promissora de obter percepções teóricas sobre os meandros da evolução darwiniana. Entretanto, a teoria ganhou força e agora pode

${ }^{56}$ MAYNARD SMITH, John \& PRICE, George R. The Logic of Animal Conflict. Nature, Vol. 246 (1973): 1518.

57 MAYNARD SMITH, John. The Theory of Games and the Evolution of Animal Conflicts. Journal of Theoretical Biology, Vol. 47 (1974): 209-21.

${ }^{58}$ MAYNARD SMITH, John. Evolution and the Theory of Games. American Scientist, Vol. 64 (1976): 41-45.

${ }^{59}$ MAYNARD SMITH, John. Evolution and the Theory of Games. Cambridge: Cambridge University Press, 1982.

${ }^{60}$ Idem. Ibidem., p. 1.

${ }^{61}$ Idem. Ibidem., p. 2. 
ser considerada como um campo de estudos independente dentro da matemática aplicada, relacionada ao estudo da evolução de sistemas dinâmicos não-lineares associados a situações de interação estratégica (consciente ou não) que envolvem múltiplos tipos de agentes.

Em termos matemáticos, jogos evolutivos são exemplos de sistemas dinâmicos ${ }^{62}$. A grosso modo, um sistema é dinâmico quando seu estado se modifica com o passar do tempo ${ }^{63}$. No caso da evolução darwiniana, o aspecto dinâmico do sistema pode ser relacionado às mudanças ambientais, e essa é a razão que torna a abordagem adaptativa adequada para modelar tais sistemas. A ideia central dos jogos evolutivos é que há uma dinâmica evolutiva que traduz os payoffs obtidos pelos indivíduos em uma dada geração em frequências fenotípicas herdáveis que se expressam na geração seguinte.

Ainda preciso explicar a relação existente entre a evolução adaptativa e os sistemas adaptativos complexos - um passo necessário para estabelecer a relação com a teoria evolutiva dos jogos. De acordo com a terceira propriedade de Levin, sistemas adaptativos complexos apresentam um processo autônomo que utiliza os resultados das interações entre os agentes individuais para selecionar alguns desses componentes para replicação ou aprimoramento. Essa é exatamente a descrição da lógica da evolução adaptativa por seleção natural. Nos sistemas biológicos, a evolução adaptativa ocorre através de um processo acumulativo que conduz a mudanças graduais por meio de um algoritmo que combina herança e seleção ${ }^{64}$

${ }^{62}$ HOFBAUER, J. \& SIGMUND, K. Evolutionary Game Dynamics. Bulletin of the American Mathematical Society, Vol. 40, No. 4 (2003): 479-519.

${ }^{63}$ VINCENT, T. L. \& BROWN, J. S. Evolutionary Game Theory, Natural Selection, and Darwinian Dynamics. New York: Cambridge University Press, 2005. p. 33.

64 NUSSENZVEIG, Moysés H. Introdução à Complexidade. In: NUSSENZVEIG, Moysés H. (Ed.). Complexidade \& Caos. Rio de Janeiro: Editora UFRJ / COPEA, 2003. p. 9-26; SALZANO, F. M. Evolução, Sistemas Complexos e Caos. In: NUSSENZVEIG, em um ambiente em constante mudança. Sistemas adaptativos complexos, portanto, descrevem um dos mecanismos centrais da evolução adaptativa por seleção natural.

Para meus propósitos de pesquisa, não é necessário investigar - por enquanto - os processos naturais mais básicos (essencialmente bioquímicos) sobre os quais a própria evolução adaptativa está baseada. É suficiente ter em mente que a evolução adaptativa darwiniana pode ser considerada, em si, como um exemplo de sistema complexo. De fato, o processo de seleção natural - o cerne da teoria de Darwin - pode ser considerado como um jogo evolutivo onde o sucesso de cada jogador depende não somente de seu fenótipo herdável (padrão de comportamento), mas também dos fenótipos herdáveis dos demais jogadores. Assim, mais do que um mero processo de adaptabilidade gradual, a seleção natural darwiniana pode ser interpretada como um jogo que "combina princípios evolutivos de herança com princípios ecológicos de interações entre populações"

A lógica da interdependência estratégica, que ocupa um lugar central na teoria dos jogos (não somente nos jogos evolutivos) estabelece que os resultados obtidos por um dado jogador dependem não somente de suas escolhas, mas também das escolhas dos demais jogadores. Em outras palavras, o sucesso de um determinado agente depende, portanto, do resultado de suas escolhas subjetivas e também do resultado das escolhas subjetivas dos demais agentes presentes no sistema econômico. Trabalhando com os jogos evolutivos como exemplos de sistemas adaptativos complexos, preserva-se essalógica da interdependência estratégica e, ao mesmo tempo, não se perdem os elementos da ação humana individual e subjetiva, da concepção dinâmica do tempo e do conhecimento limitado e disperso através do sistema, que

Moysés H. (Ed.). Complexidade \& Caos. Rio de Janeiro: Editora UFRJ / COPEA, 2003. p. 139-49.

${ }^{65}$ VINCENT \& BROWN. Evolutionary Game Theory, Natural Selection, and Darwinian Dynamics. p. 15. 
são elementos caros à perspectiva da Escola Austríaca de Economia e que também estão presentes, conforme vimos, em sistemas adaptativos complexos. Entretanto, quando pensamos em Economia Austríaca, evolução e complexidade, o nome que vem à mente de imediato é o de F. A. Hayek. Na seção seguinte, apresentarei e criticarei brevemente a perspectiva hayekiana e desenvolverei meu argumento central - isto é, a partir de sistemas complexos adaptativos e jogos evolutivos baseados em memes, é possível desenvolver uma abordagem ao mesmo tempo evolutiva e austríaca.

\section{III - A Seleção de Grupo na Perspectiva Austríaca de Hayek: Por Que Devemos AbANDONÁ-la}

Como ponto de partida desta seção, observo que F. A. Hayek foi influenciado pela ideia de Carl Menger (1840-1921) de que a racionalidade societal não é mais do que o resultado da agregação das racionalidades individuais privadas ${ }^{66}$. Hayek também considera que os seres humanos agem propositadamente, porém critica as exigências racionalistas que ultrapassam as capacidades da mente humana. Nesse sentido, o movimento teórico de Hayek lembra a crítica de Herbert Simon (19162001) ao Homo oeconomicus, baseada na ideia de que os indivíduos humanos são limitados em suas capacidades cognitivas e computacionais ${ }^{67}$. Em outras palavras, Hayek argumenta em favor da racionalidade, porém rejeita o racionalismo, concebido como o cerne do projeto da modernidade como a

66 ZAFIROVSKI, M. Classical and Neoclassical Conceptions of Rationality - Findings of an Exploratory Survey. The Journal of Socio-Economics, Vol. 37 (2008): 789-820. Cit. p. 804.

${ }^{67}$ SIMON, Herbert A. A Behavioural Model of Rational Choice. The Quarterly Journal of Economics, Vol. 69, No. 1 (1955): 99-118. Cit. p. 99. ideia de que a racionalidade humana poderia moldar adequadamente as instituições do mundo social. Além das escolhas motivadas por propósitos, as ações humanas, de acordo com Hayek, também são moldadas por regras sociais que estabelecem quais ações são permitidas $^{68}$.

Quando Hayek argumenta em favor da existência de "regras sociais" que permitem ou proíbem certas ações individuais, ele refere-se à tradição. Mas o que dá origem às tradições? Claramente, Hayek distingue entre:

[...] os sistemas de regras de conduta que governam o comportamento dos membros individuais de um grupo (ou os elementos de qualquer ordem), por um lado, e, por outro lado, a ordem do padrão de ações resultante para o grupo como um todo. [...] Assim, para explicar o funcionamento da ordem social em um dado momento do tempo, as regras para a conduta individual precisam ser assumidas como dadas. Contudo, essas regras foram selecionadas e formadas pelos efeitos que elas exercem sobre a ordem social ${ }^{69}$.

Como foi que essas regras foram "selecionadas e formadas"? Hayek é explícito: pelos efeitos que elas exercem sobre a ordem social. Esta evolução cultural faz com que os grupos humanos sejam selecionados "pelos efeitos de suas práticas habituais, efeitos a respeito dos quais os indivíduos não estavam e não poderiam ter estado conscientes"70. Em outras palavras, "normas sociais e instituições evoluem porque proporcionam vantagens aos grupos que as adotam" ${ }^{\prime 71}$. Dessa maneira, a seleção natural

${ }^{68}$ HAYEK, F. A. Studies in Philosophy, Politics and Economics. Chicago: University of Chicago Press, 1967. p. 66-69.

${ }^{69}$ Idem. Ibidem., p. 66; 72.

${ }^{70}$ HAYEK, F. A. The Origins and Effects of Our Morals: A Problem for Science. In: NISHIYAMA, C. \& LEUBE, K. (Eds.). The Essence of Hayek. Stanford: Hoover Institution Press, 1984. p. 318-19.

${ }^{71}$ ANDREOZZI, Luciano. Hayek Reads the Literature 
das regras, para Hayek, deve ser seleção de grupo. Luciano Andreozzi ressalta que:

[...] jamais ocorreu [a Hayek] que as normas sociais e as instituições poderiam evoluir devido ao fato de que proporcionam benefícios aos indivíduos, e não necessariamente aos grupos que as $\operatorname{adotaram}^{72}$.

De fato, Hayek assume a existência de três níveis evolutivos: a evolução genética como a base da ordem nas formas primitivas do comportamento social; uma evolução secundária, dos produtos da inteligência humana e do conhecimento; e um terceiro nível correspondente à evolução cultural, que explica a origem das regras de conduta, da moral e das tradições, e que não é "nem geneticamente condicionado, nem elaborado racionalmente"73. A teoria hayekiana das instituições está imersa neste terceiro nível evolutivo, o nível da evolução cultural, localizado entre o instinto e a razão ${ }^{74}$, sendo que tal evolução é impulsionada pela seleção de grupo, que modela a competição entre as ordens sociais, e também pelo aparecimento espontâneo de ordens sociais a partir das relações sociais entre indivíduos autointeressados.

A seguir, discutirei com mais detalhes os problemas decorrentes do recurso à ideia de seleção de grupo. Por enquanto, observo que, por adotar a seleção de grupo, Hayek não fornece uma unidade explícita sobre a qual

on the Emergence of Norms. Constitutional Political Economy, Vol. 16 (2005): 227-47. Cit. p. 227.

${ }^{72}$ Idem. Ibidem., p. 229.

73 WITT, Ulrich. Evolutionary Economics and Evolutionary Biology. In: KOSLOWSKI, P. (Ed.). Sociobiology and Bioeconomics: The Theory of Evolution in Biological and Economic Theory. Berlin: Springer, 1999. p. 279-298. Cit. p. 283.

74 WITT, Ulrich. The Theory of Societal Evolution: Hayek's Unfinished Legacy. In: BIRNER, J. \& VAN ZIJP, R. (Eds.). Hayek, Co-Ordination and Evolution: His Legacy in Philosophy, Politics, Economics and the History of Ideas. London: Routledge, 1994. p. 178189. Cit. p 182. a seleção adaptativa opera. Isto acrescenta, à sua teoria, um elemento de indefinição e ambiguidade que não permite considerála como mais do que uma mera analogia da evolução. Conforme observado por Witt, "o problema com a construção teórica de Hayek é que não oferece explicação a respeito do processo crucial de aprendizado social e da transmissão das regras de conduta"75. Se a seleção de grupo é o que produz a evolução das culturas, mesmo que as ordens sociais que competem na savana de Hayek decorram das coisas novas que os indivíduos estão constantemente fazendo de maneiras diferentes, não temos como saber como o processo de aprendizado social ocorre e, mais especificamente, como as regras de conduta são transmitidas entre os indivíduos. O tratamento dessas questões, que são essenciais para um tratamento evolutivo adequado, é impossibilitado pela utilização da seleção de grupo.

Além de F. A. Hayek, outros autores desenvolveram argumentos evolutivos para estudar fenômenos sociais, políticos e culturais. Por exemplo, Peter J. Richerson e Lesley Newson analisam o fenômeno religioso sob uma perspectiva evolutiva baseada na seleção que ocorre em vários níveis ao mesmo tempo ${ }^{76}$. Chris Boehm estabelece uma analogia entre sistemas morais e os cromossomos, einterpreta os grupos humanos como as unidades de seleção e adaptação em seu estudo antropológico cultural do igualitarismo e altruísmo ${ }^{77}$. Orion A. Lewis e Sven Steinmo argumentam que a mudança institucional gradual pode ser entendida

75 WITT, Ulrich. Evolutionary Economics and Evolutionary Biology. p. 284.

76 RICHERSON, P. J. \& NEWSON, L. Is Religion Adaptive? Yes, No, Neutral. but Mostly We Don't Know. In: SCHLOSS, J. \& MURRAY, M. J. (Eds.). The Believing Primate: Scientific, Philosophical, and Theological Reflections on the Origin of Religion. New York: Oxford University Press, 2009. p. 100-17.

${ }^{77}$ BOEHM, C. Hierarchy in the Forest: Egalitarianism and the Evolution of Human Altruism. Cambridge: Harvard University Press, 1999. 
como um processo evolutivo multinível ${ }^{78}$. O que todos esses autores têm em comum é que caem facilmente na armadilha da seleção de grupo ou multinível ${ }^{79}$.

Embora diversos fatores possam participar do processo de evolução adaptativa, tais como a "interação da genética de populações, da seleção natural e de uma rede subjacente de constrangimentos bioquímicos" $" 80$, a seleção natural darwiniana é, de longe, o fator mais significativo e, a grosso modo, é a única teoria científica de que dispomos para explicar a adaptação evolutiva ${ }^{81}$, mesmo que não seja o único processo que causa a evolução.

Se isso é praticamente consensual na comunidade científica, uma questão mais controversa diz respeito à unidade de seleção na evolução adaptativa. Mark Ridley observa que, embora a vida possa estar organizada em vários níveis (nucleotídeos, genes, células, órgãos, organismos, grupos sociais, espécies e níveis mais altos), é pertinente perguntar sobre qual desses níveis a seleção natural opera, se é que opera sobre algum deles ${ }^{82}$. De fato, adaptações decorrentes da seleção natural podem beneficiar vários níveis de organização, mas isto não significa que a seleção natural opere nesses níveis, ou mesmo em mais de um nível ao mesmo tempo (i.e., seleção multinível).

Como processos sociais costumam ocorrer em vários níveis ao mesmo tempo, à primeira vista parece óbvio que a ideia

78 LEWIS, O. A. \& STEINMO, S. How Institutions Evolve: Evolutionary Theory and Institutional Change. Polity, Vol. 44, No. 3, p. 314-339, 2012.

${ }^{79}$ PINKER, Steven. The False Allure of Group Selection. Edge. 18 Jun. 2012.

${ }^{80}$ OLSON-MANNING, C. F.; WAGNER, M. R. \& MITCHELL-OLDS, T. Adaptive Evolution: Evaluating Empirical Support for Theoretical Predictions. Nature Reviews Genetics, Vol. 13, No. 12 (2012): 867-77. p. 867.

${ }^{81}$ DAWKINS, Richard. The Extended Phenotype: The Long Reach of the Gene. Oxford / New York: Oxford University Press, 1999.

82 RIDLEY, Mark. Evolution. Malden: Blackwell Publishing, 2004. p. 293. de seleção multinível, desenvolvida pelos sociobiólogos David Sloan Wilson e Edward Osborne Wilson ${ }^{83}$, seria a mais adequada para a investigação de processos sociais. Dado que a seleção multinível inclui a seleção no nível do grupo, é pertinente observar que a ideia de que a seleção natural possa operar nos grupos (como conjuntos de indivíduos) pode levar à conclusão de que a seleção natural age sobre os traços que tornam um dado grupo social mais "forte" do que outro grupo social (no sentido de melhor adaptado ao ambiente). Segundo Richard Dawkins, em sua contundente crítica da postura de E. O. Wilson:

"seleção de grupo" [é] a visão mal definida e incoerente de que a evolução é impulsionada pela sobrevivência diferencial de grupos inteiros de organismos. Ninguém duvida que alguns grupos possam sobreviver melhor do que outros. O que é controverso é a ideia de que a sobrevivência diferencial dos grupos impulsiona a evolução, assim como ocorre com a sobrevivência diferencial dos indivíduos. [...] É importante não confundir esta questão-comoWilson lamentavelmente faz - com a questão de se os indivíduos se beneficiam por viverem em grupos. É claro que sim. [...] Isso não é seleção de grupo: cada indivíduo se beneficia. [...] o bem-estar do grupo é estritamente incidental. ${ }^{84}$

Assim, a seleção natural opera sobre os indivíduos, e não sobre os grupos, e não há motivos convincentes para considerar o contrário. Mas sobre quais indivíduos? Dawkins é direto a respeito deste ponto: os genes. "A sobrevivência dos genes é o que conta, em última análise, na seleção natural, $e$ o mundo torna-se repleto de genes que são bons em sobreviver" $"$. O argumento de Dawkins baseia-se no fato de que os genes são os únicos replicadores verdadeiros, o que não

${ }^{83}$ WILSON, D. W. \& WILSON, E. O. Rethinking the Theoretical Foundation of Sociobiology. The Quarterly Review of Biology, Vol. 82, No. 4 (2007): 327-348.

${ }^{84}$ DAWKINS, Richard. The Descent of Edward Wilson. Prospect Magazine. 24 May 2012.

${ }^{85}$ Idem. Ibidem. 
ocorre com organismos individuais, grupos, espécies ou ecossistemas.

Se eu rejeito completamente a seleção de grupo e multinível, isso ocorre por duas razões. Primeiro, porque estou de acordo com o posicionamento científico de Dawkins a respeito da insustentabilidade da ideia de que a seleção possa operar para além do gene. Segundo, porque a insistência na seleção de grupo é o que impede a compatibilização da perspectiva austríaca - que necessariamente associo ao individualismo metodológico - com uma abordagem verdadeiramente evolutiva. De acordo com Viktor Vanberg:

[...] Aparentemente, e de forma estranha, Hayek apela para uma noção coletivista funcionalista quando enfatiza que, na evolução cultural, um processo de seleção de grupoé ‘da maior importância' [...]. Esse apelo de Hayek à noção coletivista-funcionalista de um processo de evolução cultural que opera no nível do grupo [...] contrasta com o individualismo metodológico explícito que de outro modo informa seus trabalhos ${ }^{86}$.

No entanto, pode-se evitar a seleção de grupo. Para tanto, é necessário definir uma unidade sobre a qual o processo de seleção opera. No caso da evolução biológica, tal unidade existe e, conforme vimos, é o gene. Entretanto, estou totalmente de acordo com Dawkins, que afirma que a seleção natural não deveria restringir-se à evolução biológica: " $\mathrm{O}$ Darwinismo é uma teoria muito grande para estar confinada ao contexto estreito do gene" ${ }^{\prime 87}$. O que proponho, então, é que, para desenvolver uma perspectiva evolutiva adequada à modelagem por meio de jogos evolutivos, é necessário especificar uma unidade replicadora sobre a qual o algoritmo da seleção possa operar. Por lidar com processos evolutivos que alegadamente ocorrem por meios não genéticos, adoto a proposta de Dawkins dos memes, que podem ser definidos como unidades autorreplicáveis de transmissão de

${ }^{86}$ VANBERG, Viktor J. Rules and Choice in Economics. London and New York: Routledge, 1994. p. 85.

${ }^{87}$ DAWKINS. The Selfish Gene. informações culturais ${ }^{88}$. Tal como os genes, os memes são autorreplicáveis e respondem a pressões seletivas, porém carregam ideias culturais e expressões cognitivas de práticas institucionais e tradicionais. Por serem replicadores de informação cultural ${ }^{89}$, memes são adequados para a aplicação dos princípios da evolução adaptativa para explicar fenômenos culturais e para estudar processos de evolução cultural ${ }^{90}$.

Em seu influente livro de 1976, The Selfish Gene, Dawkins afirma que "a transmissão cultural é análoga à genética no que [...] pode dar origem a uma forma de evolução" 1 . O argumento de Dawkins consiste na constatação de que o que os genes têm de especial é o fato de serem replicadores. Assim, pode haver outros replicadores que, sob condições adequadas, poderiam fundamentar outros processos evolutivos. No caso específico da cultura humana, ele chamou esses replicadores de memes:

Exemplos de memes são músicas, ideias, frases de efeito, roupas, modas, formas de fazer potes ou de construir arcos. Assim como os genes se propagam no pool genético, saltando de corpo a corpo por meio de espermatozóides ou óvulos, os memes se propagam no pool memético saltando de cérebro a cérebro através de um processo que, em um sentido amplo, pode ser chamado de imitação. ${ }^{92}$

Dado que alguns memes são mais bemsucedidos do que outros em sua capacidade

\footnotetext{
${ }^{88}$ Idem. Ibidem. 35. Cit. p. 228. Press, 1999.

${ }^{91}$ DAWKINS. The Selfish Gene. p. 189.

${ }^{92}$ Idem. Ibidem., p. 192.
}

89 SHERMER, Michael. The Skeptic's Chaplain: Richard Dawkins as a Fountainhead of Skepticism. In: GRAFEN, A. \& RIDLEY, M. (Eds.). Richard Dawkins: How a Scientist Changed the Way We Think. Oxford and New York: Oxford University Press, 2006. p. 227-

90 GRAHAM, G. Genes: A Philosophical Inquiry. London / New York: Routledge, 2002; BLACKMORE, Susan. The Meme Machine. Oxford: Oxford University 
de replicação no pool memético, Dawkins afirma que a memética funciona de maneira semelhante à seleção natural biológica:

Conjecturo que os complexos de memes co-adaptados evoluem da mesma maneira que os complexos de genes co-adaptados. A seleção favorece os memes que exploram seu ambiente cultural em vantagem própria. Este ambiente cultural consiste dos outros memes que também estão sob seleção. $\mathrm{O}$ pool memético, portanto, apresenta atributos de um conjunto evolutivo estável, que novos memes consideram difícil de invadir. ${ }^{93}$

Devo admitir, entretanto, que os memes são replicadores não-materiais difíceis de apreender e de mensurar por meios diretos ${ }^{94}$. De qualquer modo, o caráter abstrato dos memes facilita o seu tratamento matemático e computacional, e sua conceitualização como unidades autorreplicáveis de seleção cultural apresenta a vantagem adicional de possibilitar o tratamento de fenômenos sociais por meio de uma abordagem evolutiva que imediatamente evita a seleção de grupo.

Finalmente, a relação entre a memética e a teoria evolutiva dos jogos pode ser ilustrada por um dos temas mais estudados por meio da ideia de memes: a evolução das linguagens naturais. De acordo com Karl Wärneyrs, memes linguísticos devem ser abordados por meio da lógica dos jogos evolutivos:

[...] devemos deixar para trás a lógica da teoria dos jogos convencional e incorporar os jogos à configuração mais abrangente de uma sociedade cujos membros encontram, repetidamente, situações semelhantes. [...] consideraremos as linguagens como memes, os análogos dos genes no mundo das ideias e comportamentos. Ao invés

\footnotetext{
93 Idem. Ibidem., p. 199.

${ }^{94}$ Há pesquisas recentes indicando que a evolução memética poderia ser mensurada adequadamente utilizando tecnologias de neuroimagem em experimentos altamente controlados, desenhados para estudar os substratos neurológicos de sua inicialização e replicação. A esse respeito, ver: MCNAMARA, A. Can We Measure Memes? Frontiers in Evolutionary Neuroscience, Vol. 3, No. 1, p. 1-7, 2011.
}

de nos preocuparmos com as escolhas de jogadores racionais no sentido da teoria padrão dos jogos, olhamos agora diretamente para as propriedades de sobrevivência e estabilidade dos diversos memes de linguagem em um cenário no qual precisam competir entre si pela atenção dos agentes ${ }^{95}$.

Em seu estudo, Wärneyrd também reconheceu que convenções informacionais podem ser formalizadas utilizando jogos evolutivos. A partir deste exemplo, tornase claro que a evolução memética pode ser estudada utilizando jogos evolutivos ao menos o caso da evolução (cultural) das linguagens naturais.

Em termos mais gerais, a equação do replicador ${ }^{96}$ - que modela a dinâmica do replicador-éutilizada na teoria evolutiva dos jogos para descrever o processo de seleção, ou como os fenótipos comportamentais mais bem sucedidos difundem-se na população $0^{97}$. Martin A. Nowak e Karl Sigmund afirmam que a dinâmica do replicador também pode descrever processos de seleção memética:

A dinâmica do replicador baseia-se no pressuposto da reprodução genética, clonal, mas essas dinâmicas e suas variantes também podem descrever a difusão de estratégias por meio de mecanismos nãogenéticos tais como aprendizado, imitação, ou outras formas de evolução cultural ${ }^{98}$.

Assim, o conceito matemático de dinâmica do replicador indica que os processos de

95 WÄRNEYRD, K. Language, Evolution, and the Theory of Games. In: CASTI, J. L. \& KARLQVIST, A. (Eds.). Cooperation and Conflict in General Evolutionary Processes. New York: John Wiley \& Sons, 1994. p. 405-422. p. 410.

96 Não é necessário desenvolver o formalismo matemático neste artigo, então remeto o leitor ao trabalho de HOFBAUER, J. \& SIGMUND, K. Evolutionary Game Dynamics.

97 Idem. Ibidem., p. 482.

98 NOWAK, M. A. \& SIGMUND, K. Evolutionary Dynamics of Biological Games. Science, Vol. 303, No. 5659 (2004): 793-99. Cit. p. 796. O itálico é meu. 
seleção memética podem ser modelados e estudados utilizado jogos evolutivos.

Em suma, o elo fraco na proposta teórica evolutiva de Hayek reside exatamente em sua utilização consciente e deliberada da ideia de seleção de grupo. Defendo que abandonar a seleção de grupo possibilita uma abordagem evolutiva que resgata o individualismo metodológico subjetivo. É necessário, contudo, trabalhar com uma unidade adequada de seleção. Quem proporciona essa unidade é Richard Dawkins, com a sua proposta de memes como unidades autorreplicantes de evolução cultural. Chego, assim, à finalização de meu argumento. Interpretando jogos evolutivos como exemplos de sistemas complexos adaptativos e, introduzindo o meme como unidade de seleção - ao invés do grupo - defendo que é possível desenvolver uma abordagem ao mesmo tempo evolutiva e austríaca, que satisfaz os critérios da tríade de Iorio. Resta tecer alguns comentários a respeito de por que tal proposta é pertinente para o desenvolvimento da Escola Austríaca de Economia.

\section{Considerações Finais: A Economia Austríaca no SÉculo XXI}

Assim como Stephen Hawking afirmou que estamos no século da ciência da complexidade, a Escola Austríaca no século XXI não pode privar-se da interação dialógica com áreas tais como a matemática e as ciências naturais. A possibilidade do desenvolvimento de uma abordagem austríaca e evolutiva, mediante a utilização de jogos evolutivos interpretados como exemplos de sistemas adaptativos complexos, apresenta-se como uma via promissora para atualizar a produção acadêmica austríaca diante da atividade científica contemporânea.

Contudo, além da pertinência teórica suscitada pela discussão que levanto neste artigo, é importante identificar algumas áreas de aplicabilidade imediata para a abordagem que apresentei aqui. Uma possibilidade que se destaca consiste na aplicação da abordagem aus- tríaca evolutiva a questões que dizem respeito ao estudo das organizações da estratégia empreendedora. Desenvolvendo a partir da teoria de Peter G. Klein do empreendedorismo como julgamento ${ }^{99}$, o empreendedor precisa realizar julgamentos em um ambiente complexo, genuinamente incerto e em constante mudança, e seu sucesso depende da sua capacidade de julgamento proporcionar vantagens adaptativas em comparação com os julgamentos de seus concorrentes. Trata-se de um caso adequado para um tratamento utilizando jogos evolutivos. Uma tal abordagem poderia incluir alguma concepção de empreendedorismo como adaptação, tal como sugerido por Theodore W. Schultz ${ }^{100}$ (1902-1998). Há ainda questões mais teóricas sobre a relação entre Economia Austríaca evolutiva e o estudo da firma de negócios. Klein observa que ${ }^{101}$, de acordo com Gerald P. O'Driscoll e Mario J. Rizzo, um marco mais evolutivo é necessário para entender como as firmas respondem à mudança ${ }^{102}$.

Outra aplicação imediata da abordagem delineada neste artigo diz respeito ao estudo da origem e evolução de instituições. O tratamento seminal de Hayek, a esse respeito, está contaminado pela seleção de grupo. Argumentei que é possível, contudo, eliminar esse aspecto controverso e trabalhar com uma perspectiva evolutiva que resgata o papel fundamental das ações individuais subjetivas, o que abre o caminho para um tratamento mais adequado das questões acerca de como ocorre o processo de aprendizado social e como as regras de conduta são transmitidas. Devo dizer que a contribuição de

${ }^{99}$ KLEIN, Peter G. O Capitalista e o Empreendedor: Ensaios sobre Organizações e Mercados. Trad. Claudio A. Téllez-Zepeda. São Paulo: Instituto Ludwig von Mises Brasil, 2015.

${ }^{100}$ SCHULTZ, T. W. The Value of the Ability to Deal with Disequilibria. Journal of Economic Literature, Vol. 13 (1975): 827-46; SCHULTZ, T. W. Investment in entrepreneurial ability. Scandinavian Journal of Economics, Vol. 82 (1980): 437-48.

${ }^{101}$ KLEIN. O Capitalista e o Empreendedor. p. 47.

${ }^{102}$ O'DRISCOLL, Gerald P. \& RIZZO, Mario J. The Economics of Time and Ignorance. London: Basil Blackwell, 1985. p. 124. 
Hayek, apesar da utilização de seleção de grupo e com todos os problemas decorrentes, teve o mérito de ampliar o escopo da Escola Austríaca de Economia para questões mais abrangentes sobre a evolução cultural subjacente aos processos sociais e de mercado. Hayek também teve a perspicácia para antecipar, ainda nos anos 1970, diversos temas que são de interesse atual no estudo dos sistemas complexos. Essas contribuições não podem ser minimizadas. Se desenvolvi, neste artigo, uma crítica à abordagem de Hayek, meu objetivo foi unicamente atentar para os problemas associados à utilização da ideia de seleção de grupo, e mostrar que tais problemas podem ser contornados mediante a utilização de uma perspectiva evolutiva baseada em uma unidade de seleção mais apropriada.

Há, ainda, alguns temas que precisam ser desenvolvidos em pesquisas subsequentes, para dar continuidade a este trabalho. Primeiramente, o aprofundamento das discussões epistemológicas que dizem respeito ao status da Escola Austríaca diante do que está acontecendo nas ciências naturais contemporâneas, que estão bem distantes do ideal positivista do século XIX e da primeira metade do século XX. Segundo, a proposta que avancei, de utilizar a ideia de memes como unidades autorreplicantes de evolução cultural no desenvolvimento de uma abordagem ao mesmo tempo austríaca e evolutiva, resolve o problema da seleção de grupo, porém levanta outros questionamentos que não devem ser negligenciados. Existe a necessidade de enfrentar o problema de como mensurar adequadamente o papel dos memes nos processos de evolução cultural adaptativa. Dado que já há propostas que envolvem a utilização de ferramentas experimentais de uso corrente na neurosciência (tais como a ressonância magnética funcional e outras técnicas de neuroimagem ${ }^{103}$ ), pode-se aprofundar as pesquisas nessa direção, promovendo uma integração mais intensa entre a Economia Austríaca, a neurociência e - mediante o emprego de jogos (evolutivos) - a economia experimental, na linha que vem sendo

${ }^{103}$ MCNAMARA. Can We Measure Memes? desenvolvida por autores como Vernon L. Smith ${ }^{104}$. Como próximo passo e seguimento natural desta pesquisa, estou desenvolvendo trabalhos nesta direção mais específica ${ }^{105}$.

Em 1959, o físico Richard Feynman (19181988) proferiu uma palestra intitulada "There's Plenty of Room at the Bottom", a respeito da possibilidade de manipular átomos individuais de forma direta ${ }^{106}$. Atualmente, acompanhamos maravilhados, dia após dia, os avanços no campo da nanotecnologia. Da mesma maneira, à primeira vista a ideia de fomentar um diálogo entre a Escola Austríaca e as ciências naturais contemporâneas pode parecer um tanto estranha, não somente pelo tradicional afastamento dos austríacos com respeito a esses temas, mas ainda mais devido às referências que faço a áreas e conceitos aparentemente tão díspares quanto "jogos evolutivos", "física dos sistemas complexos", "neurociência", "memes" e "economia experimental". Entretanto, talvez estejamos em um momento no qual possamos, inspirados no exemplo de Richard Feynman, também dizer que "há muito espaço na parte inferior". Cabe a nós o trabalho de exploração. cos

104 SMITH, Vernon L. Papers in Experimental Economics. Cambridge: Cambridge University Press, 1991; SMITH, Vernon L. Bargaining and Market Behavior: Essays in Experimental Economics. New York: Cambridge University Press, 2000.

105 Por razões de cientificidade, considero da maior importância dedicar atenção às possibilidades de elaborar abordagens experimentais compatíveis com os pressupostos austríacos. Vejo que uma possibilidade imediata apresenta-se na triangulação entre Neurociência, Economia Experimental e Jogos Evolutivos.

${ }^{106}$ FEYNMAN, Richard. There's Plenty of Room at the Bottom. Palestra no California Institute of Technology. Dec. 1959. Disponível em: <http://www.its.caltech. edu/ feynman/plenty.html> 